\title{
GESTÃO DEMOCRÁTICA: UMA ABORDAGEM NO CONTEXTO ESCOLAR
}

\author{
DEMOCRATIC MANAGEMENT: AN APPROACH IN THE SCHOOL CONTEXT
}

\author{
Rodi Narciso \\ Faculdade Venda Nova do Imigrante, MG, Brasil. E-mail: rodynarciso1974@gmail.com
}

\section{Catyane Roberta Hauth}

Prefeitura Municipal de Sinop, MT, Brasil. E-mail: catyhauth@gmail.com

\section{Jacob Patriche Cunba}

Prefeitura Municipal de Sinop, MT, Brasil. E-mail: coord.patrick@gmail.com

DOI: https://doi.org/10.46550/amormundi.v2i3.103

Recebido em: 16.04.2021

Aceito em: 29.05.2021

\begin{abstract}
Resumo: O presente estudo objetiva refletir esta temática táo discutida nas IE - Instituiçôes de Ensino, que é a Gestâo Democrática. Este tema provoca uma reflexáo quanto ao papel inerente ao gestor adepto a esta modalidade de gestão no contexto escolar (centralidade organizacional entre direção - coordenação - Secretaria de Educação), e, ao mesmo tempo, assume um compromisso de transformar a realidade escolar num espaço democrático, onde seja possível a articulação de ideias, estabelecer diálogos, levando em consideração os diferentes pontos de vista. Como respaldo, será trazido à luz o conceito de Gestão Democrática participativa, a função da escola básica diante deste novo formato de gestão, bem como as Leis Municipais e a práxis desta. Para tanto, nos ancoraremos em artigos e literaturas afins, que sedimentam essa prática dentro do âmbito escolar. Contudo estes desafios, ligados a esta nova prática de gestão, devem estar ligados ao contexto das políticas sociais e econômicas, influenciando o sistema educacional, que por sua vez norteia a gestão escolar.
\end{abstract}

Palavras-chave: Democrática. Gestão. Escola Básica. Práxis.

Abstract: The present study aims to reflect this theme so discussed in the IE - Teaching Institutions, which is Democratic Management. This theme provokes a reflection on the inherent role of the manager adept at this type of management in the school context (organizational centrality between direction - coordination Department of Education), and, at the same time, assumes a commitment to transform the school reality into a democratic space, where it is possible to articulate ideas, establish dialogues, taking into account different points of view. As support, the concept of participatory Democratic Management will be brought to light, the role of the elementary school in the face of this new management format, as well as the Municipal Laws and its praxis. To do so, we will anchor ourselves in articles and related literature, which consolidate this practice within the school environment. However, these challenges, linked to this new management practice, must be linked to the context of social and economic policies, influencing the educational system, which in turn guides school management.

Keywords: Democracy. Management. Basic School. Praxis. 


\section{Introduçáo}

Z mbora tenhamos conhecimento com relação as diversas lutas em prol da democratização

Cdas escolas públicas, elas apenas tiveram força a partir da década de 1980 as quais resultaram na aprovação dos "Princípio de Gestão Democrática do Ensino Público", assegurado pelo Art. 206 da C.F. de 1988.

A LDB (9394/96) regulamenta as diretrizes gerais para a educação pública em seu Art. 90 onde são estabelecidas metas para a elaboração para o Plano Nacional de Educação, garantindo o direito à Gestão Democrática no Art. 14º, desta Lei.

O PNE- Plano Nacional de Educação por sua vez, discute planos e metas que direcionarão à qualidade de ensino, bem como assegurando a Gestáo Democrática.

Ao se abordar o tema Gestão faz-se necessário conceituá-lo, e diferenciá-lo de Gestão Escolar, para trazemos os mesmos em conformidade com o módulo pedagógico Profuncionário, "Gestão: Forma de planejar, organizar, dirigir, controlar e avaliar um determinado projeto [...]."

Gestão escolar: forma de organizar o trabalho pedagógico que implica a visibilidade de objetivos e metas dentro da instituição escolar; aplicar gestão colegiada de recursos materiais e humanos, planejamento de suas atividades, distribuição de funçôes e atribuiçóes, na relação interpessoal de trabalho, e partilha do poder; Diz respeito a todos os aspectos da gestáo colegiada e participativa da escola e na democratização da tomada de decisóes (BRASIL, 2012, MINISTÉRIO DA EDUCAÇÃO).

Independente do ramo de atividades que se atue é necessário que se formulem estratégias para atingir objetivos. Com esta referência, há importância de uma boa gestão nas instituiçôes de ensino de nosso país.

Respaldados nesta afirmação tem-se como tema de pesquisa a Gestão Democrática no contexto escolar, tendo por foco a aplicabilidade da mesma no ensino básico.

No decorrer desta produção pretende-se evidenciar qual é a concepção de Gestão Democrático-Participativa, sua aplicabilidade na escola de educação básica, as Leis que a regulamentam e sua práxis. Para tanto, será realizada uma pesquisa de cunho bibliográfico, onde serão apresentados os conceitos desta modalidade de gestão, sua importância e real função na realidade do âmbito escolar.

Portando, os desafios dessa nova prática, para esclarecimento, devem estar intrinsecamente ligados ao contexto das políticas sociais e econômicas, as quais influenciam substancialmente no mundo corporativo e no sistema educacional, e por consequência na gestáo escolar.

\section{Caminhos para uma gestáo democrática}

Muito se tem falado com relaçáo à Gestáo Democrática. Mesmo antes da criação das principais leis que nos dão suporte, algumas Unidades de Federação já lutavam por uma escola mais autônoma, visando tal gestão. Assim antes de se iniciar a fala sobre gestão escolar democrática, primeiramente deve-se entender sua conceituação.

A LDB (Art. 14), busca efetivar a regulamentação da Gestão Democrática do ensino público, oferecendo autonomia às unidades para, em sintonia, definir a operacionalização de tal processo. Processo este que deve levar em consideração o envolvimento dos profissionais de 
educação, assim como a comunidade escolar. Em paralelo a esta participação, a escola através da elaboração de seu projeto pedagógico e a atuação em conselhos escolares ou equivalentes deve buscar oferecer igualdade e garantia de acesso ao saber historicamente acumulado e o pleno exercício da cidadania. Na perspectiva da LDB, a Gestão Democrática circunscreve-se sob alguns aspectos da vida acadêmica.

Art. 14. Os sistemas de ensino definirão as normas da Gestão Democrática do ensino público na educação básica, de acordo com as suas peculiaridades e conforme os seguintes princípios.

I - Participação dos profissionais da educação na elaboração do projeto pedagógico da escolar.

II - Participação das comunidades escolar e local em conselhos escolares ou equivalentes.

De acordo com Cury apud Pinto e Zainko (2008, p. 18), o termo gestão vem de gestio, que, por sua vez, vem de gerere, que significa "trazer em si, produzir". Como o próprio autor afirma, gestão é mais do que administrar e organizar uma instituição, é ser líder.

No entanto, para somar a esse conceito e compreensão de gestão, vale acrescer a contribuição ilustríssima de Cury (2002), quando ressalta que este termo também provém do verbo latino gero, gessi, gestum, gerere, os quais significa levar sobre si, chamar a si, exercer, gerar. Sendo, assim, como em uma das formas de se ver este substantivo derivado do verbo, gestatio, que é o mesmo que gestação se percebe a forma pela qual se traz de dentro de si algo novo, diferente. "Desta mesma raiz provêm os termos genitora, genitor, germen. A gestão, neste sentido, é, por analogia, uma geração similar àquela pela qual a mulher se faz mãe ao dar a luz a uma pessoa humana”. (Cury, 2002, p. 164).

O gestor-líder exerce papel fundamental no desenvolvimento promissor das atividades escolhidas na instituição, mas para que estas tenham realmente sucesso, é necessário que o gestor envolva-se não somente profissional, mas também pessoalmente, proporcionando o crescimento e fortalecimento desta Gestão Democrática. Esta organização escolar deve estar em contato com os seus docentes, discentes e comunidade em geral, voltando suas ações para os bons resultados da educação, dividindo as tarefas e integrando açôes e ideias, a fim de solidificar um grande compromisso com significados e valores reais para nossa sociedade.

Conforme definido em Lück (2009, p. 75),

[...] alguns elementos emergem como características comuns de atuaçóes de liderança efetiva e que, portanto, compóem o seu significado: • Influência sobre pessoas, a partir de sua motivaçáo para uma atividade. • Propósitos claros de orientação, assumidos por essas pessoas. • Processos sociais dinâmicos, interativos e participativos. - Modelagem de valores educacionais elevados. • Orientação para o desenvolvimento e aprendizagem contínuos.

Nas unidades escolares, os gestores devem atuar em consonância com a equipe escolar (docentes, discentes, apoio e comunidade). Sendo necessária a participação efetiva dos conselhos e secretarias das diferentes esferas.

Nas palavras de Almeida (2017, p. 5),

A formação de gestores [...] não (está) ligada apenas ao papel do gestor escolar, mas sim, a todos os membros que atuam dentro dos espaços escolares e também são líderes: professores em suas salas de aula, inspetores que cuidam dos alunos, 
equipe das merendeiras, limpeza, enfim, até os nossos educandos, entre os quais sempre temos aquela figura que mais se destaca e lidera os pares.

Diante do acima exposto, presume-se que os líderes escolares atendam ao princípio de Gestão Democrática apresentada pela Constituição Federal de 1988, assim como na LDB Lei n. 9.394/96, e no Plano Nacional de Educação (PNE) 2014-2024. Esse modelo de gestão pressupóe um formato organizacional de modo que a equipe escolar atue coletivamente na propagação dos objetivos educacionais. E não como afirma Paro (2001, p. 18-19) onde, na escola que "se diz" democrática, há na verdade profissionais ocupando postos de direção,

[...] que se dizem democratas apenas porque são "liberais" com alunos, professores, funcionários ou pais, porque lhes "dão abertura" ou "permitem" que tomem parte desta ou daquela decisão. Mas o que esse discurso parece não conseguir encobrir totalmente é que, se a participação depende de alguém que dá abertura ou permite sua manifestação, então a prática em que tem lugar essa participação não pode ser considerada democrática, pois democracia não se concede, se realiza: não pode existir "ditador democrático.

Ainda com o foco nas leis que garantem o ensino gerido por uma Gestão Democrática, vale ressaltar que é de suma importância conhecer algumas orientaçóes de como se dá esse processo de forma efetiva no Município de Sinop, locus desse estudo, garantida pela Lei $\mathrm{n}^{\mathrm{o}}$ $815 / 2004$ de 30 de setembro de 2004, até então, onde garante que o diretor, assim como o coordenador, ambos serão escolhidos pela comunidade escolar, por meio do voto da comunidade e demais profissionais da educação.

Para facilitar o trabalho do gestor nas escolas e também o papel da Educação no país, alguns países da América Latina criaram Declaraçôes. Conforme a Declaração de Santiago de 1993 apud Zainko e Pinto (2008, p. 24),

Nos novos delineamentos da gestão, o diretor é responsável pelo funcionamento do estabelecimento de ensino e pelos resultados de aprendizagem dos alunos. A partir da Declaração de Santiago 1993, ocorre uma evolução no modelo de gestáo, pois aos aspectos quantitativos foram acrescidos aspectos qualitativos, evidenciando-se uma preocupação com a formação de quadros para exercer com competência o novo modelo de gestão, objetivando imprimir eficiência e eficácia na realização de serviços públicos.

A constituição da Gestão Democrática na escola fundamenta-se no conhecimento da finalidade da escola em si. No Art. 205 C.F. é garantido ser direito de todos "o pleno desenvolvimento da pessoa, seu preparo para a cidadania e sua qualificação para o trabalho". Ou seja, é obrigação da escola oferecer e garantir o livre acesso e permanência do aluno nos bancos escolares.

A LDB traz em seu Art. 22 que a Educação Básica tem como finalidade desenvolver o educando, assegurando-lhe a formação comum e indispensável ao pleno exercício de sua cidadania, fornecendo meios para sua progressão acadêmica.

Sendo assim, para garantir o papel social da escola, o gestor deve propiciar aos alunos não apenas a apropriação dos conteúdos acadêmicos, mas, a inserção de saberes tecnológicos, éticos, jurídicos e econômicos.

Ao comentar sobre o papel social da escola, não se pode deixar de mencionar a função da escola básica respaldada pela Gestão Democrática nos dias atuais. 
A escola, tida como campo específico de educação, não é considerado um elemento alheio à situação humana, mas uma instituição social, necessária à vida, lugar onde vivem boa parte do tempo crianças e adolescentes.

Para Paulo Freire (1993, p. 117) "A educação será tão mais plena quanto mais esteja sendo um ato de conhecimento, um ato político, um compromisso ético e uma experiência estética".

Portanto, são muitas as tarefas atribuídas à escola; sendo que a principal é educar e formar cidadãos para a vida. Como se isso não fosse o bastante, cabe aos gestores trabalhar para que haja ordem nesse espaço, e para isso é imprescindível uma Gestão Democrática e participativa.

Para a efetivação desta modalidade de gestão não basta o bom funcionamento da escola, é de suma importância que o gestor responsável, tenha conhecimento da realidade na qual está inserido, sabendo quem são os integrantes desta instituição, suas culturas e metodologias favoráveis e apropriadas de modo a atender a demanda.

A instituição dos colegiados nas unidades educativas são resultado de discussóes e implementaçôes deste novo modelo de gestão (democrática). Werle (2003, p. 51 e 52) indica que os conselhos escolares são considerados como uma forma de organização da comunidade, $\mathrm{e}$ os destaca-se como princípios norteadores.

Rodrigues (1987, p. 73) comenta que a escola, nas pessoas de seu colegiado, é um

[...] órgáo coletivo de tomada de decisóes e analises dos problemas [..]. O colegiado representa, também, uma mudança tanto nos processos de tomada de decisões, administrativas e pedagógicas, como nas formas de relacionamento com a comunidade ou com os órgãos superiores da administração educacional.

Em conformidade com a missão da escola ora explicitada, Prais (1996) apresenta como base de uma Gestão Democrática o referencial teórico com o intuito de fundamentar a educação, transformando a práxis educativa em uma prática social e histórica, construída por intermédio das relações sociais.

O autor supracitado ainda comenta que a pedagogia histórico-crítica é concebida como uma pedagogia progressista, que permite a análise e compreensão do processo de administração colegiada.

Os fundamentos deste colegiado, divididos em tópicos, mas diretamente interrelacionados, se fortalecem através de pilares de construção desta autonomia escolar e para a formação do novo cidadão. Bartnik (2012, p. 132-133), os apresenta na seguinte sequência: "A gestão da escola e a instituição de colegiados; A gestão da escola e construçáo coletiva do projeto pedagógico; A gestão da escola e a reflexão permanente do processo de ensino-aprendizagem”.

Parente e Lück (200, p. 159), apresentam o colegiado escolar como sendo "um órgáo coletivo, consultivo e fiscalizador, e [que] atua nas questôes técnicas, pedagógicas, administrativas e financeiras da unidade escolar." Este órgão é de natureza consultiva o qual compreende diferentes estruturas colegiadas.

No decorrer destas linhas tem-se tratado das diferentes esferas de uma Gestão Democrática, como se concebe, órgáos que fazem parte, conceitos e aplicabilidade. No entanto, não se comentou sobre o perfil que o gestor dentro dessa modalidade de gestão deve ter.

O gestor escolar na atualidade precisa ser bastante flexível e atuante no campo administrativo, pedagógico e social, pois a escola vive dias de inúmeras turbulências. Os principais 
requisitos para um bom gestor escolar em nossos dias são, de acordo com Victor (2014, p. 1):

A capacidade sócio-relacional; Tecer relaçóes e faze-las prosperar; Compreender o outro; Detectar talentos; Solucionar conflitos. Mediar acordos de cooperação; Fazer parcerias internas e externas; Dirigir, dando orientação; Motivar o grupo.

Ser líder requer, além do trabalho em equipe, o compromisso e envolvimento total enquanto profissional. Portanto, um bom gestor deve seduzir sua equipe de profissionais, de modo a garantir o cumprimento de suas metas e objetivos, para o bom andamento da dinâmica escolar.

Um dos papéis de um líder é nortear as emoçóes de sua equipe. Se estas forem impelidas positivamente, o dispara; se incitarem negativamente; perderão o rumo. Quando os líderes estimulam as emoçôes de maneira positiva, extraem o melhor de cada um - os autores chamam de ressonância. Quando as emoçóes são canalizadas de modo negativo, os lideres geram dissonância. Ainda segundo Victor (2014, n.p.) apud Goleman (2002),

[...] grandes líderes nos mobilizam. Inflamam nossa paixão e inspiram o melhor de nós. Quando tentamos explicar a causa de tamanha eficácia, pensamos em estratégia, visāo ou ideias poderosas. Na verdade, eles atuam em um nível mais fundamental: os grandes líderes atuam por meio das emoçôes.

\section{Consideraçóes finais}

Pode-se concluir que o ato de "estar gestor" não é muito fácil. Construir uma Gestão Democrática representa absorver a ideia de multiculturalidade, aceitando o outro e se prédispondo a aprender com ele. É necessário transformar interesses individuais em interesses coletivos, buscando a participação de todos os envolvidos na construção desse processo.

Esta reflexão, não teve a intenção de oferecer fórmulas de como proceder na gestão participativa, mas propor, de forma sucinta, um breve estudo, a fim de que, cada gestor, conhecedor de sua realidade escolar, possa refletir sobre este local enquanto um espaço de relaçóes sociais, caracterizado e modificado pelas relaçôes diversas e compreensóes dos atores aí presentes.

Cabe, segundo esse aspecto, ao gestor, o dever de orientar e conduzir a ação dos membros da sua comunidade a fim de reconhecer que a função de mais alta relevância dentro desse contexto é promover o aluno. Promover não exprime "deixar passar", mas sim, dar condiçôes para que o mesmo possa crescer e completar-se como ser humano e como cidadáo.

\section{Referências}

ALMEIDA, Aline Martins de. Apostila da Disciplina de Fundamentos de Organizaçáo e o Cotidiano Escolar..IBFPOS, Joinvile SC, 2017.

BRASIL, Lei n. 9394, de 20 de dezembro de 1996. Estabelece as diretrizes e bases da educação nacional.

BRASIL, Constituiçáo (1988). Constituição da República Federativa do Brasil. Brasília, DF: Senado Federal: Centro Gráfico, 1988.

\section{BRASIL. Ministério da Educaçáo. Secretaria de Educaçáo Profissional e Tecnológica.}


Gestáo em Educaçáo Escolar/ Luiz Fernandes Dourado, -4ed. atualizada e revisada- Cuiabá: Universidade Federal de Mato Grosso/ Rede e-Tec Brasil 2012, 102 p: il- (Curso técnico de formaçáo para os funcionários da educaçáo. Profuncionário.

CURY, C.R.J. Gestão Democrática da educação: exigências e desafios. Revista Brasileira de Política e Administraçáo da Educaçáo. São Bernardo do Campo, v. 18, n. 2, jul./dez. 2002a.

DEMO, P. Participação é conquista: noçóes de política social e participativa. $4^{\mathrm{a}}$ ed. São Paulo: Cortez, 1999.

DOURADO, L.F. A escolha de dirigentes escolares: políticas da gestão da educação no Brasil. In: FERREIRA, N(org). Gestáo Democrática da educaçáo: atuais tendências, novos desafios. 2a ed. São Paulo: Cortez, 2000.

LÜCK, H. Dimensóes de gestáo escolar e suas competências. Curitiba: Editora Positivo, 2009.

MONTEIRO. A. Reis. Paulo Freire Pedagogo do Direiro à Educaçáo. Edição de Autor, 2014.

PARO, Vitor. Gestáo Escolar, 2005

RODRIGUES, N. Por uma nova escola: o transitório e o permanente na educaçáo. 6.ed. São Paulo: Cortez; Autores Associados, 1987.

VICTOR, A. A. Gestão democrática e participativa na escola. Postado em11/05/2014. Disponível em:< https://webcache.googleusercontent.com/ search?q=cache:uP7LoUnpfwoJ:https://www.portaleducacao.com.br/educacaofisica/artigos/56866/gestao-democratica-e-participativa-na-escola $+\& c d=1 \& \mathrm{hl}=$ ptBR\&ct=clnk\&gl=br. Acesso em: Setembro de 2019.

WERLE, F.O.C. Conselhos escolares: implicaçóes na gestáo da escola básica. Rio de Janeiro. DP\&A, 2003.

ZAINKO, Maria Amélia Sabbag; PINTO, Maria Lúcia Accioly Teixeira. Gestáo da Instituição de Ensino e Açáo Docente. 2008, Curitiba, IBPEX. Conselhos Escolares, caderno $1 ; 2004$. 